\title{
Effects of the Friction Coefficient on Sealing Performance of Packer Element
}

\author{
Baolong Qu \\ College of Chemistry and Environmental Engineering \\ Yangtze University \\ Jingzhou, China \\ e-mail: qubaolong_78@163.com
}

\begin{abstract}
An optimal design of the packer element contact pressure is conducted to gain further insight into the packer seal mechanism and avoiding fracture. A double elements packer is investigated using the finite element method, where an orthogonal testing method is utilized to study the effects of the friction coefficient. The results show that the packer element radial friction coefficient had the greatest effect on contact pressure than other factors. Decreasing the packer element friction coefficient or increasing the support ring friction coefficient is conducive to forming the double packer elements seal and increasing the maximum contact pressure working range. However, there is additionally a slight decrease in the value of maximum contact pressure. The experiment results show that decreasing the friction coefficient of the packer element will avoid fracture effectively. The results of the study provide valuable insight into the importance of packer design optimization.
\end{abstract}

Keywords-packer element; friction coefficient; orthogonal test; contact pressure; finite element method

\section{INTRODUCTION}

A packer is a necessary down-hole tool used in the process of oil layering. Its core component is the packer element. When the packer element supports an axial load such as gravity or pressure from a liquid, it experiences a relatively large deformation, which produces a larger contact pressure and forms a seal between the packer element and the casing, resulting in sealing of the annular gap and isolation of the production layer. American Thomas et al proposed that the load capacity of the packer element is a function of the pressure (or stress) that exists during the sealing process. To achieve and maintain the seal, the pressure (or stress) should be greater than the working value. The maximum contact pressure between the packer element and the casing will directly determine the quality of the packer seal; therefore, research on the factors that affect the contact pressure is extremely important to understand the seal mechanism and to optimize packer design.

The material, molding process, size, shape, and load mode of the packer element each influence the contact pressure between the packer element and the casing to a different extent. There are several published solutions to the contact pressure problem [1-3], but the literature does not consider frictional contact between the packer element and the casing. Recently, scholars have begun to focus on the effect of various frictional coefficients for the contact pressure [4-7], therefore providing through numerical simulation more accurate results than suggested by classical theory. However, the new methods do not consider the difference between the transverse and radial coefficient of the packer element or the effect of the frictional coefficient between the support ring and the tubing.

This paper reports the results of a systematic study conducted using a double packer. The finite element software ANSYS, along with an orthogonal testing method, is used to investigate how and to what extent the frictional coefficient of the component near the packer element is affected by a contact pressure. The research introduces concrete measures and countermeasures for improving the contact pressure of packer element.

\section{MATERIAL MODEL AND CALCULATION MODEL}

\section{A. Material Model}

Packer element is made primarily of rubber materials, specifically, hyperelastic materials, which deform nonlinearly when subjected to an external force $[1,8]$. Available research on the mechanical properties of swelling rubber is limited $[9,10]$. With the development of the finite element method (FEM) and computer technology, the mechanical properties of rubber materials have been widely researched. Currently, the strain energy density function is commonly used in FEM to indicate the mechanical properties of rubber materials, as shown in the hyperelastic constitutive models of Neo-Hookean [11], Yeoh [12] and Mooney-Rivlin [13,14]. This research adapts the Mooney-Rivlin model, which simulate uniaxial tensile stress and strain, to study the friction contact behavior of packer element.

The strain energy density function $W$ of a rubber material is a function of the right Cauchy-Green deformation tensor invariant $I_{1}, I_{2}, I_{3}$, that is,

$$
W=W\left(I_{1}, I_{2}, I_{3}\right)
$$

Where

$$
\left\{\begin{array}{l}
I_{1}=\lambda_{1}^{2}+\lambda_{2}^{2}+\lambda_{3}^{2} \\
I_{2}=\lambda_{1}^{2} \lambda_{2}^{2}+\lambda_{2}^{2} \lambda_{3}^{2}+\lambda_{3}^{2} \lambda_{1}^{2} \\
I_{3}=\lambda_{1}^{2} \lambda_{2}^{2} \lambda_{3}^{2} \\
\lambda_{i}=1+\gamma_{i}
\end{array}\right.
$$

$\lambda_{i}$ is the principal stretch ratio, $\gamma_{i}$ is the main strain.

Based on the stress-strain relationship, Mooney M J [13] established a constitutive relationship for the rubber material via phenomenological theory. Because the rubber materials are isotropic and incompressible, $I_{3} \equiv 1$. Rivlin R 
S [14] studied the model with respect to the Mooney theory and developed the strain energy density model of incompressible materials, where $C_{i j}$ is a mechanical property constant.

$$
W=\sum_{i=0, j=0}^{\infty} C_{i j}\left(I_{1}-3\right)^{i}\left(I_{2}-3\right)^{j}
$$

The Mooney-Rivilin model of rubber materials can simulate most of the mechanical behavior of the rubber materials. From the calculation, the Mooney-Rivlin model can be transformed into a two-, three-, five-, or nineparameter model. The two-parameter model is the most commonly used.

$$
W=C_{10}\left(I_{1}-3\right)+C_{01}\left(I_{2}-3\right)
$$

The model provides a good description of the mechanical properties of rubber materials when compression deformation is about $30 \%$ and completely satisfies the performance calculation of packer element materials.

In the Mooney-Rivlin model with two parameters, the Rivlin coefficient $C_{10}$ and $\mathrm{C}_{01}$ are positive constants that can be determined by a uniaxial tensile test of the material.

When the material is incompressible, the relationship between the Rivlin coefficient and Young's modulus is determined as follows [15]:

$$
E=6\left(C_{10}+C_{01}\right)
$$

Testing shows that the ratio of $C_{01}$ to $C_{10}$ is a constant and ranges from 0.25 to 0.5 . $\mathrm{C}_{01}$ and $\mathrm{C}_{10}$ can be calculated using formula (5) when Young's modulus is known. The research presented in this paper fixes the ratio at 0.5 . When Young's modulus (E) is $21.2 \mathrm{MPa}$ and $C_{10}$ is $2.36 \mathrm{MPa}$, then $C_{01}$ is $1.18 \mathrm{MPa}$.

Wherever Times is specified, Times Roman or Times New Roman may be used. If neither is available on your word processor, please use the font closest in appearance to Times. Avoid using bit-mapped fonts if possible. TrueType 1 or Open Type fonts are preferred. Please embed symbol fonts, as well, for math, etc.

\section{B. Calculation Model}

The packer element, support ring, tubing, and casing of the double elements packer investigated in this study are axially aligned. Additionally, the loads are applied axially; therefore, the problem can be reduced to a twodimensional one for each component. The model is applied to a section through the axis. The component of interest is the packer element; therefore, the geometric model shows the packer element and the component surrounding the packer element, as shown in Fig.1.

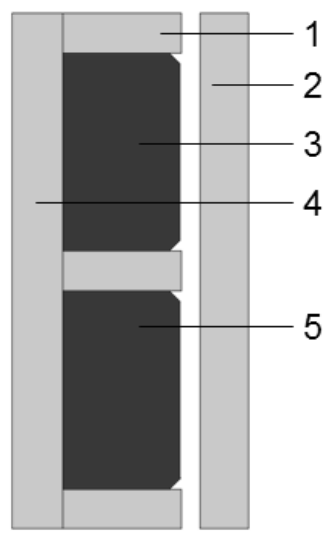

Figure 1. The structure schematic diagram of double elements packer 1- Support ring, 2- Casing, 3- Upper packer element, 4- Tubing, 5Lower packer element

The upper and lower end of the tubing and casing are considered fixed when the packer is working. The lower support ring is fixed; the upper support ring has seal pressure applied, causing the packer element to expand radially. As the seal pressure increases, the packer element comes into contact with the casing. When the pressure reaches a certain value, a sealed state is achieved; thus, the annulus between the tubing and the casing is sealed. The end angle of the packer element is $45^{\circ}$, and the length is 6 $\mathrm{mm}$. The remaining geometric and mechanical parameters are shown in Table I.

TABLE I.

THE PACKER PARAMETERS

\begin{tabular}{cccccc}
\hline Component & $\begin{array}{c}\text { Inside diameter } \\
\text { //mm }\end{array}$ & $\begin{array}{c}\text { Outer diameter } \\
\text { /mm }\end{array}$ & $\begin{array}{c}\text { Height } \\
\text { /mm }\end{array}$ & $\begin{array}{c}\text { Young's modulus } \\
\text { /MPa }\end{array}$ & Poisson's ratio \\
\hline Tubing & 51.0 & 70.0 & - & $2.1 \times 105$ & 0.25 \\
Casing & 121.4 & 139.7 & - & $2.1 \times 105$ & 0.25 \\
Support ring & 70.0 & 114.5 & 15 & $2.1 \times 105$ & 0.25 \\
Packer element & 70.0 & 114.0 & 75 & 21.2 & 0.49 \\
\hline
\end{tabular}

\section{NUMERICAL CALCULATION}

The relationship between the packer element and the surrounding components is best expressed as a frictional contact problem; therefore, ANSYS can be used to analyze the contact pressure of the packer element. The packer element is a rubber material with a large deformation capacity; therefore, the hyperelasticity element Plane 182, which is a quadrilateral axisymmetric element with four simulation nodes, is adopted. The tubing, casing, and support ring are metal materials with small deformations; therefore, the element Plane 42, which is also a quadrilateral axisymmetric element with four nodes, is adopted. Element size is set to $4 \mathrm{~mm}$, and the geometric model is meshed as shown in Fig .1. Mesh results are shown in Fig .2. The total number of elements is 1065 , and the total number of nodes is 1288 . Each node has two degrees of freedom in the $\mathrm{X}$ and $\mathrm{Y}$ directions of the Plane 42 and Plane 182 elements; hence, the total degrees of freedom in the finite element model after being meshed is 2576.

Because the packer element has frictional contact with the corresponding position of tubing, support ring, and casing, the support ring has contact with the tubing. All the contacts are face-to-face. The contact element uses Contact 171, and the target element uses Target 169. 


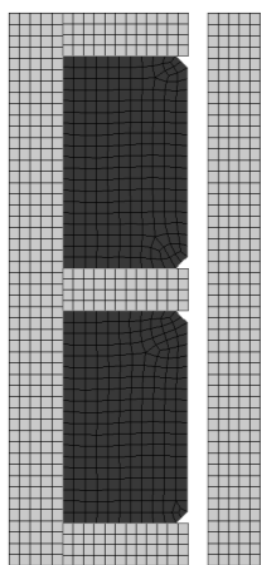

Figure 2. Finite element model

Packer element is a polymer material with a molecular weight greater than 200,000. Rubber products are usually made by compression molding, which can easily cause macromolecular chains to be locally aligning along certain directions during the molding process. Additionally, because of the difference in the mold and molding shrinkage, the transverse and radial surface roughness of the packer element will be different. Therefore, the packer element has different frictional coefficients in the transverse and radial directions.

In the simulation of the packer element in a sealed state the positions that have frictional contact behavior are the support ring and the tubing, the packer element and the support ring (transverse), the packer element and the tubing (radial), and the packer element and the casing (radial). The frictional coefficient is divided into three cases: the support ring and tubing $(f l=0.1)$, the packer element transverse $(f 2=0.5)$, and the packer element radial $(f 3=0.5)$

Based on the working state of the packer, the displacement constraint is set for the upper and lower end of the tubing and casing, the transverse displacement constraint is set the for all the support rings, and the radial displacement constraint is set for the lower support ring. A vertical displacement load of $25 \mathrm{~mm}$ is applied to the upper support ring. A simulation of the mechanical behavior of the packer element in the sealed state can now be performed.

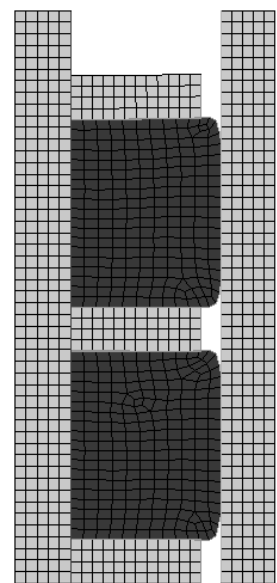

Figure 3. Deformed shape of the packer element

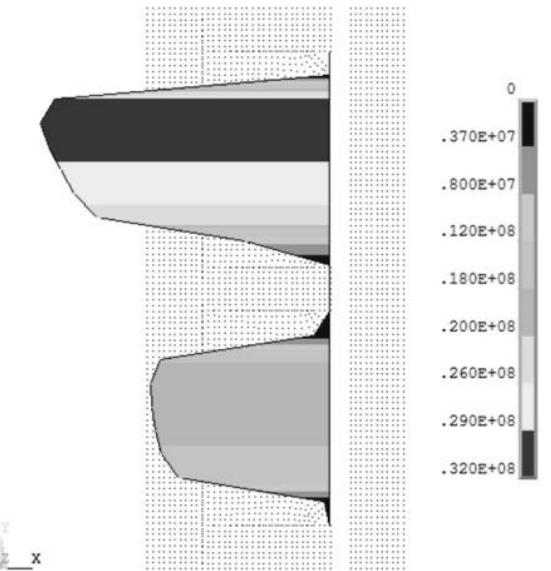

Figure 4. Contact pressure distribution of the packer element and the casing

The deformed shape result of the packer element is shown in Fig .3. According to the figure, the packer element had a great deformation, contacted with the casing sufficiently, and formed a sealing state.

Fig .4 shows the contact pressure distribution of the packer element and the casing. According to the data from the numerical calculation, the maximum pressure of the upper element is $30.61 \mathrm{MPa}$, the lower is $18.87 \mathrm{MPa}$, and the maximum pressure difference between the upper and lower elements is $11.74 \mathrm{MPa}$. The upper element is easy to fracture by the large contact pressure, but the sealing of the lower element is difficultly by the small pressure.

\section{ORTHOGONAL OPTIMAL DESIGN FOR FRICTION COEFFICIENT}

\section{A. Orthogonal test plans}

The frictional coefficient is divided into three cases: the support ring and tubing $(f l)$, the packer element transverse $(f 2)$, and the packer element radial $(f 3)$. Each friction coefficient has three levels. An orthogonal test is carried out and produces results with three factors and three levels. The contact behavior between the packer element and the tubing, the support ring, and the casing represents the rubber-metal material friction. The contact behavior between the support ring and the tubing is metal-metal material friction. The frictional coefficient of the latter is relatively small. Specific friction coefficients for each factor and level are shown in Table II.

TABLE II.

EFFECT FACTORS AND LEVELS IN THE ORTHOGONAL TEST

\begin{tabular}{ccccc}
\hline Levels & Friction coefficients & f1 & f2 & f3 \\
\hline & & & & \\
& First level & 0.05 & 0.3 & 0.3 \\
& Second level & 0.10 & 0.5 & 0.5 \\
Third level & 0.15 & 0.7 & 0.7 \\
\hline
\end{tabular}

\section{B. Orthogonal test results}

The main mechanism of the packer is that the packer element bears an axial pressure, resulting in radial expansion and deformation, and it will make contact with the casing. When the contact pressure reaches a certain value, a sealed state in the annulus between the tubing and casing is achieved. In this state, only the packer element 
area where the contact pressure is maximal acts as a seal. That is, the quality of the seal depends on the size and range of the maximum contact pressure. Additionally, to form a simultaneous seal with two packer elements and to avoid seal failure, the maximum contact pressure between two elements should have similar values for engineering applications.
Using the orthogonal test, the research in this paper determines the maximum contact pressure difference (referred to as the pressure difference in the following) between the upper and lower packer elements. From the three factors and the three levels of the orthogonal test, the effects of the frictional coefficient are analyzed for the pressure difference in different parts of the double packer elements. Test plans and test results are shown in Table III.

TABLE III

ORTHOGONAL TEST PLANS AND RESULTS

\begin{tabular}{|c|c|c|c|c|}
\hline Test number $\quad$ Friction coefficient & $\begin{array}{c}\text { Support ring } \\
\text { and tubing(f1) }\end{array}$ & $\begin{array}{l}\text { Packer element } \\
\text { transverse(f2) }\end{array}$ & $\begin{array}{c}\text { Packer } \\
\text { element } \\
\text { radial(f3) }\end{array}$ & $\begin{array}{c}\text { Results /MPa } \\
\text { (pressure difference) }\end{array}$ \\
\hline 1 & $1(0.05)$ & $1(0.3)$ & $1(0.3)$ & 8.64 \\
\hline 3 & 1 & $3(0.7)$ & $3(0.7)$ & 15.43 \\
\hline 4 & $2(0.10)$ & 1 & 2 & 11.29 \\
\hline 7 & $3(0.15)$ & 1 & 3 & 14.45 \\
\hline 8 & 3 & 2 & 1 & 8.88 \\
\hline 9 & 3 & 3 & 2 & 11.8 \\
\hline I - Sum of the first level test result & 35.81 & 34.38 & 26.43 & \\
\hline II - Sum of the second level test result & 35.55 & 35.97 & 34.83 & \\
\hline III- Sum of the third level test result & 35.13 & 36.14 & 45.23 & \\
\hline
\end{tabular}

According to the orthogonal test, the test results are analyzed by the range method, which is a simple calculation with strong intuition, and the results of the analysis are shown in Table III.

The following results are observed from the data:

(1) In the three tests in which the factor levels of frictional coefficient $f l$ between the support ring and the tubing are the same, $f 1=0.05$ is compared with $f 1$ $=0.15$, and the pressure difference decreases by 0.23 $\mathrm{MPa}$.

(2) In the three tests in which the factor levels of packer element transverse frictional coefficient $f 2$ are the same, $f 2=0.3$ is compared to $f 2=0.7$, and the pressure difference increases by $0.59 \mathrm{MPa}$.

(3) In the three tests in which the factor levels of packer element radial frictional coefficient $f 3$ are the same, $f 3=0.2$ is compared to $f 3=0.6$, and the pressure difference increases by $6.27 \mathrm{MPa}$.

According to the analytical results, the following conclusions can be drawn:

(1) For the pressure difference, the packer element radial frictional coefficient has the greatest effect, followed by the packer element transverse frictional coefficient, and the frictional coefficient between the support ring and tubing has the least effect.

(2) Decreasing the packer element radial and transverse frictional coefficient or increasing the frictional coefficient between the support ring and tubing will assist in reducing the pressure difference, but the latter has little effect.

By adjusting the friction coefficient, if the pressure difference is reduced, the maximum contact pressure of the upper and lower packer elements can be reduced to some extent.

\section{Optimal design}

According to the above analysis, optimal design was set up: $f 1=0.15, f 2=f 3=0.1$. The optimal condition adjusts the friction coefficient to decrease the pressure difference.

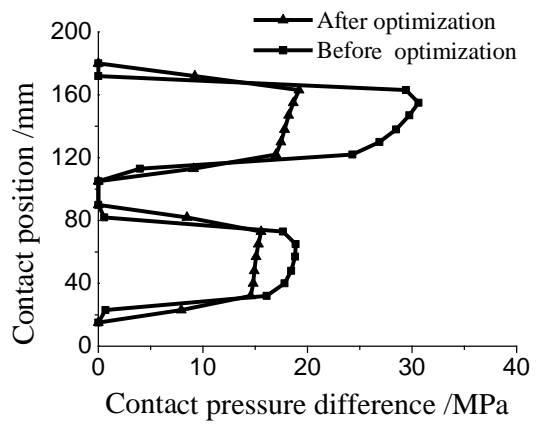

Figure 5. Contact pressure distribution before and after the optimal design

Fig .5 shows the contact pressure distribution of the packer element and the casing before and after the optimal design. According to the data from the numerical calculation after the optimal design, the maximum pressure of the upper element is $19.2 \mathrm{MPa}$, the lower is $15.56 \mathrm{MPa}$, and the maximum pressure difference between the upper and lower elements is $3.64 \mathrm{MPa}$. Obviously, the pressure difference of optimal design is lower than that of original working condition. Therefore, reducing the frictional coefficient of the packer element and increasing the frictional coefficient between the support ring and the tubing will reduce the pressure difference. In addition, compared to that of original working condition, the maximum contact pressure of the tubing and the casing of optimal design is reduced by $10.41 \mathrm{MPa}$. Furthermore, by reducing the frictional coefficient of the packer element, 
the working range of the maximum contact pressure increases, which is beneficial to protect the packer element, instead of avoiding a large contact pressure in the smaller area, which causes local damage to the packer element and seal failure. The proposed conclusions are verified by the simulation results.

The conclusions can be explained. First, when the packer is sealing, the relative displacement contact between the packer element radical and surrounding component is much greater, and its friction can be regarded as sliding friction, but relative displacement is smaller in other positions, which can be regarded as static friction. Consequently, the friction coefficient of the packer element radical can be heavily affected by the contact pressure. Second, by decreasing the frictional coefficient of the packer element, the frictional force of the upper packer element can also be reduced, which is beneficial to the transmission of the setting pressure from the upper packer element to the lower packer element through the middle support ring, and it causes a decrease in the maximum pressure difference. In addition, decreasing the frictional coefficient of the packer element causes the upper and lower packer elements to work simultaneously and disperses the contact pressure; therefore, the maximum pressure difference of the packer element is reduced. Finally, the load direction is vertical to the upper support ring. Therefore, the frictional coefficient between the packer element and the support ring is lightly affected by the packer element.

In order to test and verify the correctness of number simulation, the experiment was carried out in the Zhuangxi oil production plant of the ShengLi oilfield. The oil well was selected that the packer element occurred rupture frequently, the butter was coated on the packer element to reduce the friction coefficient for the downhole operation. The experiment results show that the fracture of the packer element is avoided effectively.

\section{CONCLUSIONS}

By focusing on the packer element and utilizing the Mooney-Rivlin rubber material model, a relevant numerical model is established to achieve a numerical simulation of the double packer elements in the sealing state. Using the orthogonal test method, this paper studies the effect of the maximum contact pressure of the upper and lower packer elements on the frictional coefficient of the packer element and the surrounding components. The research results show that (1) the effect of the packer element radial frictional coefficient is greater for the contact pressure; (2) decreasing the frictional coefficient of the packer element is beneficial for the double packer to work simultaneously; (3) any measure that leads to the double packer working simultaneously leads to a reduction in the maximum contact pressure; and (4) reducing the frictional coefficient of the packer element can lead to an increase in the working range of the maximum contact pressure, which helps protect the packer element.

\section{ACKNOWLEDGMENT}

Authors acknowledge the financial support provided by National Science and Technology Major Project of China (2011ZX05036-006).

\section{REFERENCES}

[1] Guo Z P, Wang Y F, Sun B, et al. Analysis and structural improvement of the rubber part in packer in a way of non-linearity finite element[C]. In: MACE, 2011 Second International Conference on IEEE, 2011: 73-76.

[2] Liu Y Q, Guo F and Xu J P. Analyzing packer's deformation of tubular for unsetting process in HTHP Wells under variable (T, P) fields[J]. The Open Petroleum Engineering Journal, 2012, 5: 109117.

[3] Guo Z P, Wang Y F, Li Q A, et al. The FEA contact analysis of high pressure packers[J]. Advances in Mechanical and Electronic Engineering, 2012,176:119-124.

[4] Jia S P, Yan X Z. and Yang L. Frictional contact analysis of packer rubber with large deformation by finite element method[J]. Lubrication Engineering, ,2005,4: 71-74

[5] Yang X J, Yan X Z, Jia S P. Frictional contact analysis of packer rubber with large deformation based on adhesive-slip frictional contact method, J[J]. Journal of Mechanical Strength, 2006, 28: 229-234.

[6] Li B and Zhang S M. Contact pressure research of drill pipe and packer of rotating blowout preventer[J]. Applied Mechanics and Materials, 2012, 121: 3200-3204

[7] Ma W G, Zhang Y C, Zhang D B, et al, Sealing analysis of packer with double rubber[J]. China Petroleum Machinery,2010, 38(11):51-53. (in Chinese)

[8] Atkinson C, Desroches J, Eftaxiopoulos D A, et al. Wellbore stresses induced by the nonlinear deformation of an inflatable packer[J]. Journal of engineering mathematics. 2001,41(4): 305327

[9] Evers R, Young D, Vargus G, et al. Design methodology for Swellable Elastomer Packers in Fracturing Operations[C]. Offshore Technology Conference in Dexas. 2009:(6), 3710-3721.

[10] Al-Yami A S, Nasr-El-Din H A, Al-Arfaj M K, et al. Investigation of water-swelling packers[C]. CIPC/SPE Gas Technology Symposium 2008 Joint Conference in Alberta, 2008,(2): 468-478.

[11] Treloar L R G. The elasticity of a network of long chain molecules( III) [J] . Transactions of the Faraday Society, 1946 , 42(1):83-93.

[12] Yeoh O H . Some forms of the strain energy for rubber[J] .Rubber Chemistry and Technology, 1993, 66(5):754-771.

[13] Mooney M J. A theory of large elastic deform at ion[J] . Journal of Applied Physics, 1940, 11(6):582-592.

[14] Rivlin R S. Large elastic deformations of isotropic materials. IV. Further developments of the general theory[J]. Philosophical Transactions of the Royal Society of London. Series A, Mathematical and Physical Sciences, 1948, 241(835):379-397.

[15] Wang W, Deng T, Zhao S G. Determination for Material Constants of Rubber Mooney-Rivlin Model][J]. Special Purpose Rubber Products, 2004, 25(4):8-10. 